an "infinitesimal linear operator." Kolmogoroff (Mathematische Annalen, vols. 104, 108) had previously, but in less suggestive language, correlated such families of operators with infinitesimal differential operators; technically, the reviewer prefers Kolmogoroff's treatment.

The reviewer also feels that Hostinsky could have used with profit the modern theory of function spaces (von Neumann, Stone, Banach). Again, von Neumann's theory of groups of linear transformations, and Schlesinger's Lebesgue integration of matrices, might well have been sketched - and a reference to Delsarte's work is really called for.

But these defects do not prevent the book from being of the first importancein fact, probably the best available introduction to the higher theory of linear differential equations.

\title{
GARRETT BIRKHOFF
}

Économique Rationnelle. By Guillaume and Ed. Guillaume. (Actualités Scientifiques et Industrielles, nos. 504-508.) Paris, Hermann, 1937. 375 pp.

An Econometric Approach to Business Cycle Problems. By J. Tinbergen. (Actualités Scientifiques et Industrielles, no. 525.) Paris, Hermann, 1937. 73 pp.

The great increase of the last few years in statistical material relating to the phenomena of economics has brought realization that the "laws of economics" must be subjected to new scrutiny. In some cases they must be modified, in others reformulated with the introduction of new variables. In this modern adventure, to which the name of econometrics has been generically given, mathematics plays its customary central role. Although the origin of mathematical economics antedates the publication in 1838 of A. A. Cournot's classic Theory of Riches, which ushered in the justly celebrated works of Jevons, Walras, Marshall, Edgeworth, Pareto, and others of the mathematical school, econometrics in the modern sense is a new science. The books before us for review indicate the trend that modern studies are taking.

The first volume is divided into five parts: (1) Method, (2) Pure economy, (3) Pure economy in interference with the legal domain, (4) The national legal-economic domain in interference with external society, (5) Mathematical models of the economic world.

It is the last part which will be of the most interest to mathematicians, since the authors attempt to establish mathematical models for the interpretation of economic phenomena. Their point of view is taken from dynamics. The authors set up equations which represent for them "the principle of the conservation of the flux of commodities." They introduce the notion of "money liquidity" in a theory of "kinetic and potential money." Economic equilibrium conditions are formulated in terms of the differential variation in commodities. Intriguing new units are employed such as the gold-gram as a quantity of value, the gold-gram/sec. as the flux of value, the gold$\mathrm{gram} / \mathrm{man}-\mathrm{sec}$. as the density of flux.

The fundamental tenet of the authors is found in the statement: "We shall see that in attempting to create a rational economics similar to a body of doctrine such as rational mechanics, we are led similarly to search for some principle of conservation, more particularly the axiom which we shall call the 'principle of the conservation of value.'"

The prefatory material is elegantly expressed and contains much of interest to the philosophy of science. Bridgman's operational theory is regarded as an essential viewpoint for the new methods. Thus, in criticising the subjective theories of the older economists, the authors remark: "Unfortunately, their efforts have remained 
practically sterile, because of a fundamental difficulty which has not yet been resolved: their axiomatique was not 'operation.' "

The work of Tinbergen is an attempt to test statistically a mechanism of business cycle policy, which has been developed over a period of years by the author and a group of Dutch mathematical economists. The analysis considers an array of twentytwo variables, and nine "international quantities considered as data." The variables are classified under three heads: (1) prices, such as wage rates, cost of living; (2) physical quantities, such as total employment, total output; (3) value figures, such as total wages' bill, value of exports. These variables are related by twenty-two equations which "are partly of a definitional or technical nature and partly the reflection of 'direct causal relationships.' "

The monograph is devoted to a study of problems which can be formulated in terms of the mathematical system. These problems are of four kinds: (1) to determine the movements defined by the variables for a set of historically given initial values; (2) to extrapolate the natural tendencies of the system, all conditions remaining unchanged; (3) to determine the movements after a variation has been imposed in the system by some "given policy"; (4) to find the optimum variation, that is to say, to determine the "best policy."

Tinbergen's study will be of interest to those who wish to view the full complexity of the economics problem and to see one of the most heroic attempts yet made to reduce the interacting variables to a mathematical system.

H. T. DAvis

Grundlagen und Methoden der Periodenforschung. By Karl Stumpff. Berlin, Springer, 1937. $332 \mathrm{pp}$.

As the title indicates, this book deals with the basic ideas of determining the periodic properties of functions and sets of points, and the methods of applying these ideas to empirical functions and observed data. The author, well versed in such analysis from his meteorological work, has taken pains to explain the fundamentals of the subject in a thorough and readily understood manner. Then he goes on to explain in some detail how the fundamentals are best applied to empirical functions obtained from a recording instrument or a series of observations of some physical phenomena.

The problem of expressing a given function as a linear combination of a series of arbitrary functions is attacked by the method of least squares. The equations for the coefficients are derived in general, and the simplified formulas for the case of orthogonal function systems are set down for ready reference. Various function systems are then discussed. These consist of circular functions (which lead to Fourier series expansions), Legendre polynomials, Hermitian polynomials, and Laguerre polynomials.

As a first application, the methods are applied to the smoothing and interpolation of a series of observations.

Next, the technically very important case of the harmonic analysis of observations with one and two independent variables is treated, including several practical schemes for carrying out the detailed calculations.

An analysis is made of the possibility and practicability of expressing an empirical function in the form of a spectrum. The properties and methods of calculating the spectrum of a series of observations is presented.

A chapter on the application of statistical methods to the analysis of the periodic properties of empirical functions serves to introduce distribution functions, correla- 